\title{
Interaction of backfilling techniques and MTA plugs with additives: Fracture strength and adaptation analyses
}

\author{
Zeliha YILMAZ'1 , Selen KÜÇÜKKAYA EREN', Emel UZUNOĞLU1', Melahat GÖRDUYSUS ${ }^{1,2}$ \\ and Mehmet Ömer GÖRDƯYSUS ${ }^{1,3}$ \\ ${ }^{1}$ Department of Endodontics, Faculty of Dentistry, Hacettepe University 06100, Sihhiye, Ankara, Turkey \\ ${ }^{2}$ RAK College of Dental Science, RAK Medical and Health Science University, Ras Al Khaimah, UAE \\ ${ }^{3}$ University of Sharjah, College of Dental Medicine, Department of Preventive and Restorative Dentistry, Sharjah, UAE \\ Corresponding author, Zeliha YILMAZ; E-mail: dtzeliha@gmail.com
}

\begin{abstract}
The aims were to evaluate the effects of different additives on the adaptation of mineral trioxide aggregate (MTA) plugs before and after different backfilling techniques and analyze the interference of filling procedures on the fracture resistance of simulated immature teeth. The apical parts of 60 teeth were filled with MTA mixed with distilled water (DW), propylene glycol (PG) or calcium chloride $\left(\mathrm{CaCl}_{2}\right)$ and backfilled with cold lateral condensation (CLC) or warm vertical compaction (WVC). The specimens were subjected to adaptation analysis and fracture testing. $\mathrm{CaCl}_{2}$ addition resulted in poor marginal adaptation, while $\mathrm{PG}$ addition significantly decreased the fracture values $(p<0.05)$. WVC technique negatively affected the marginal adaptation of $\mathrm{MTA} \mathrm{CaCl}_{2}$ plugs and decreased the fracture values of teeth with MTA-PG plugs $(p<0.05)$. Mixing MTA with DW can be recommended as apical plug when the remaining root canal space is going to be filled with either CLC or WVC techniques.
\end{abstract}

Keywords: Apexification, Calcium silicate, Replica techniques, Root canal obturation

\section{INTRODUCTION}

Traumatic dental injuries can cause the loss of pulp vitality before development of the root is completed ${ }^{1}$. The resultant flaring root canals accompanied by thin immature dentinal walls render these teeth more prone to fracture ${ }^{1}$. Furthermore, these teeth occasionally have wide-open apices, which may be challenging to treat with conventional endodontic procedures ${ }^{1}$.

Historically, the treatment of an immature tooth with a necrotic pulp was performed with long-term calcium hydroxide placement inside the root canal system, with success rates ranging from $79-96 \% \%^{2,3)}$. However, this procedure has several drawbacks such as multiple visits, the need of patient compliance and the potential to further decrease the strength of the root ${ }^{4}$. To overcome these concerns, an alternative treatment method, one-step apexification with mineral trioxide aggregate (MTA), has been proposed ${ }^{5}$. This procedure can be completed in a single visit by applying orthograde placement of an artificial apical barrier, or plug comprised of $\mathrm{MTA}^{6}$. MTA is a calcium-silicate based material and possesses several desirable properties such as superior sealing ability, biocompatibility, and the ability to set in the presence of tissue fluids ${ }^{7}$. On the other hand, MTA presents some notable shortcomings such as difficult handling property and long setting time ${ }^{8)}$. To improve such properties of MTA, researchers have mixed it with different additives including propylene glycol (PG) and calcium chloride $\left(\mathrm{CaCl}_{2}\right)^{8 \cdot 10)}$.

Although the immediate apexification can be provided by MTA, still there is a necessity of obturating the remaining canal space for sealing purposes and providing a reinforcement of the weak structure ${ }^{11}$.
Following the apexification with MTA, backfilling techniques may affect the marginal adaptation of the apical plug. However, this issue has not been addressed in the literature. Furthermore, there is a lack of information regarding the fracture resistance of immature teeth backfilled with different techniques following the apexification with MTA including different additives. Therefore, the aims of the present study were to evaluate the marginal adaptation of MTA mixed with distilled water (DW), $\mathrm{PG}$ or $\mathrm{CaCl}_{2}$ after backfilling procedures with cold lateral compaction (CLC) or warm vertical compaction (WVC) of gutta-percha and to test the fracture strength of these simulated immature teeth. The first null hypothesis of this study was that the additives to MTA has no significant influence on the marginal adaptation of the material and the fracture resistance of simulated immature teeth. The second null hypothesis was that the backfilling technique does not affect the marginal adaptation of MTA plugs with different additives and the fracture resistance of simulated immature teeth.

\section{MATERIALS AND METHODS}

Following the ethics committee approval (Ethics Board No: GO 16/334), 80 freshly extracted, human maxillary anterior teeth with similar dimensions were used in the study. The teeth were observed under magnification to confirm that there were no resorptions, extensive caries, cracks, or deformities. The crowns and $3 \mathrm{~mm}$ apical portions were removed with discs to obtain standard length of $13 \mathrm{~mm}$ for each sample and to simulate immature root apices similar to a previous study ${ }^{12)}$. Measurements of the samples were made using a 
digital caliper (Mitutoyo, Hampshire, UK). Ten samples were left without performing any additional procedure and served as negative control. The root canals of the remaining samples $(n=70)$ were enlarged using ProTaper rotary files (Dentsply Maillefer, Ballaigues, Switzerland) up to F4 mounted on a torque-controlled reduction hand-piece (X-Smart, Dentsply Maillefer). For the simulation of immature apices, Peeso reamers (Dentsply Maillefer) between \#2 and \#6 were introduced in the root canals and a \#6 Peeso reamer was allowed to protrude $1 \mathrm{~mm}$ beyond the apex to create an apical diameter of $1.70 \mathrm{~mm}$. The root canals were irrigated using $2 \mathrm{~mL}$ of $5.25 \%$ sodium hypochlorite after each file and a final flush with $5 \mathrm{~mL}$ of $17 \%$ EDTA was made to remove the smear layer. Finally, the root canals were flushed with distilled water and dried using paper points (Dentsply Maillefer). At this point, 10 teeth were randomly selected for positive control group and remained enlarged and unfilled to simulate immature roots with thin walls. Throughout the experiments, the teeth were kept in moistened gauze.

To mimic immediate barrier formation, the apical $3 \mathrm{~mm}$ of each tooth was filled with MTA (ProRoot, Dentsply, Tulsa Dental, Tulsa, OK, USA) plugs using a hand plugger (SybronEndo, Kerr Endodontics, Orange, CA, USA) according to the groups below;

Group DW ( $n=20): 1.0$ g MTA powder was mixed with $0.35 \mathrm{~mL}$ DW.

Group PG $(n=20)$ : 1.0 g MTA powder was mixed with $0.35 \mathrm{~mL}$ liquid composed of $20 \%$ PG (Emir Kimya, Ankara, Turkey)-80\% DW by volume.

Group $\mathrm{CaCl}_{2}(n=20): 1.0 \mathrm{~g}$ MTA powder with $0.1 \mathrm{~g}$ $\mathrm{CaCl}_{2}$ (Sisco Research Laboratories, Mumbai, India) was mixed with $0.35 \mathrm{~mL} \mathrm{DW}$.

Following the placement of the materials, each surface was gently cleaned with a moist gauze in order to clean the dentin surface from any material remnants. Digital periapical radiographs from the same angles were taken from each specimen to verify the density and the location of the apical plug. The samples were kept for 7 days at $37^{\circ} \mathrm{C}$ under $100 \%$ humidity.

Following the incubation period, each experimental group was divided into 2 subgroups according to the backfilling technique applied:

Groups DW-CLC, PG-CLC and $\mathrm{CaCl}_{2}$-CLC: The remaining root canal space was backfilled using a root canal sealer (AH Plus, Dentsply, DeTrey, Konstanz, Germany) and gutta-percha (Dentsply) by CLC technique. In this technique, the sealer was mixed and inserted into the root canals using a lentulo spiral drill, and then a master cone was dipped in the sealer and introduced in the root canal until the working length. Then, accessory cones were inserted in the same manner and condensed using finger spreaders. Excess material was removed and vertical compaction was made using a cold plugger $1 \mathrm{~mm}$ below the orifice of the root canal.

Groups DW-WVC, PG-WVC and $\mathrm{CaCl}_{2}$-WVC: The sealer was mixed and inserted into the remaining root canal space using a lentulo spiral drill. Backfilling was performed with the Elements ${ }^{\mathrm{TM}}$ Free Obturation System (SybronEndo, Kerr Endodontics) at $200^{\circ} \mathrm{C}$ followed by compaction with a plugger.

Final radiographs were obtained to confirm uniform and dense obturation. The orifice of each root canal was sealed with a composite filling material (Filtek Z250, 3M ESPE, Seefeld, Germany). The teeth were stored at $37^{\circ} \mathrm{C}$ and $100 \%$ humidity for 1 week to allow the sealer setting.

\section{Marginal adaptation analysis}

Impressions of each air-dried root-ends were taken with vinylpolysiloxane precision impression material (Variotime, Heraeus Kulze, Hanau, Germany) before and after the backfillings and used as negative replicas to evaluate the effect of obturation techniques on the marginal integrity of the apical plugs according to the following 3-grade scale ${ }^{13)}$;

Score 1: Material is well adapted, defined as follows:

1. Close marginal approximation of the filling material to the dentinal wall

2. No spacing defects present at the material-dentin interface in $>70 \%$ of the circumference of the open apex (Figs. 1A and B)

Score 2: Material is moderately adapted, defined as follows:

1. Close marginal approximation of the filling material to the dentinal wall

2. Presence of spacing defects at the material-dentin interface in $30-60 \%$ of the circumference of the open apex (Fig. 1C)

Score 3: Root filling material is poorly adapted, defined as follows:

1. Poor marginal approximation of the filling material to the dentinal wall

2. Major voids and/or significant spacing defects at the material dentin interface in $>60 \%$ of the circumference of the open apex (Fig. 1D)

Negative replicas were gold-sputtered for examination in a scanning electron microscope (Nova, NanoSEM 430, FEI, Hillsboro, OR, USA). Photomicrographs were taken at $130 \mathrm{x}$ magnification. Regions of special interest were photographed at 500× magnification (Fig. 2). The scoring was done by two independent endodontists in a blind manner. When a difference occurred in the scoring of an image, the two examiners reevaluated the image and discussed it until an agreement was obtained.

\section{Fracture testing}

Following marginal adaptation analysis, the specimens were perpendicularly embedded in self-curing acrylic resin poured in identically shaped cylinders ${ }^{11,14)}$, leaving a gap of $2 \mathrm{~mm}$ between the top of the acrylic and the cemento-enamel junction. A Universal Testing Machine 

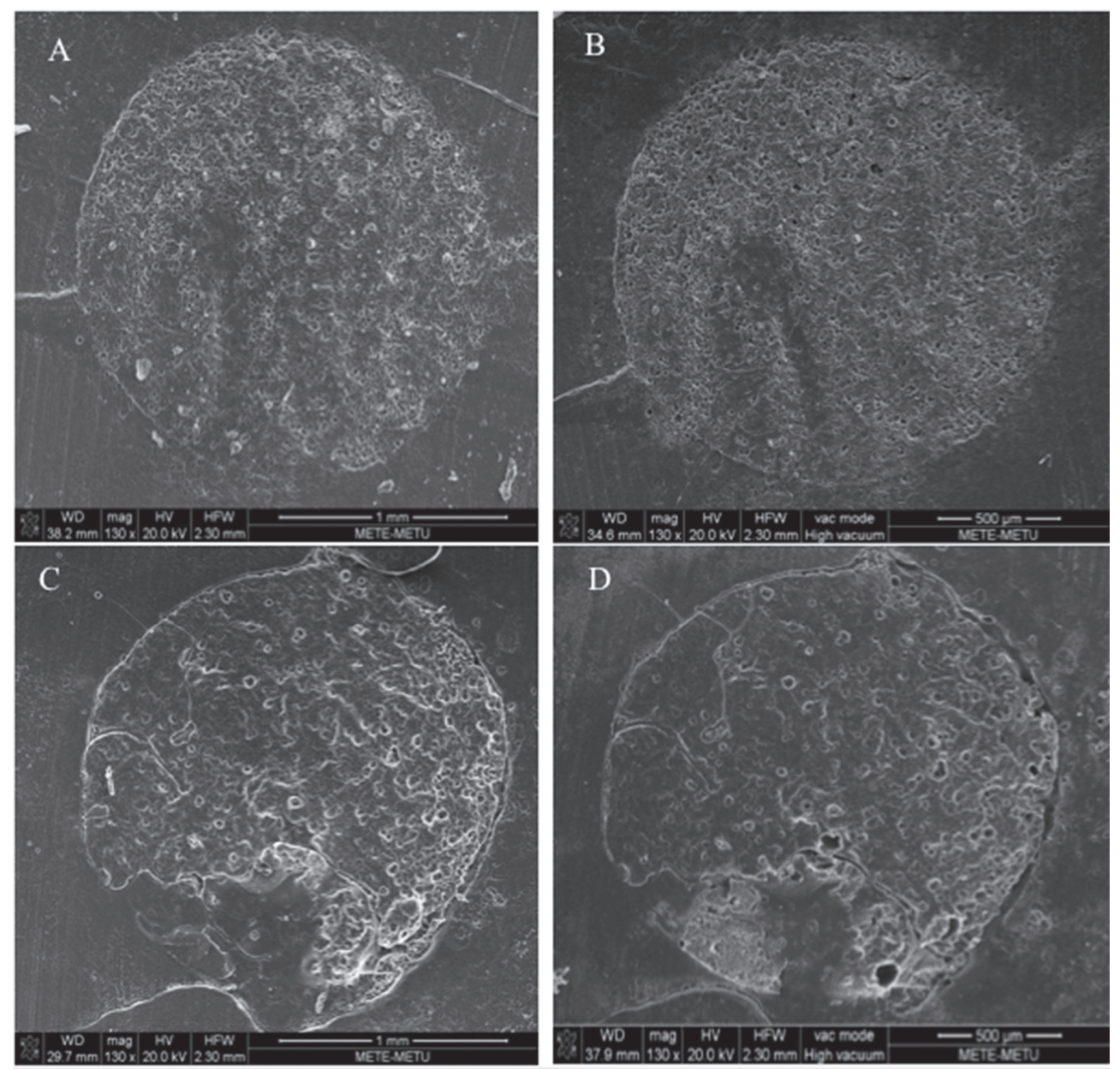

Fig. 1 Representative SEM images of the apical plugs. (A): Score 1 (before backfilling); (B): Score 1 (following backfilling); (C): Score 2 (before backfilling); (D): Score 3 (following backfilling).
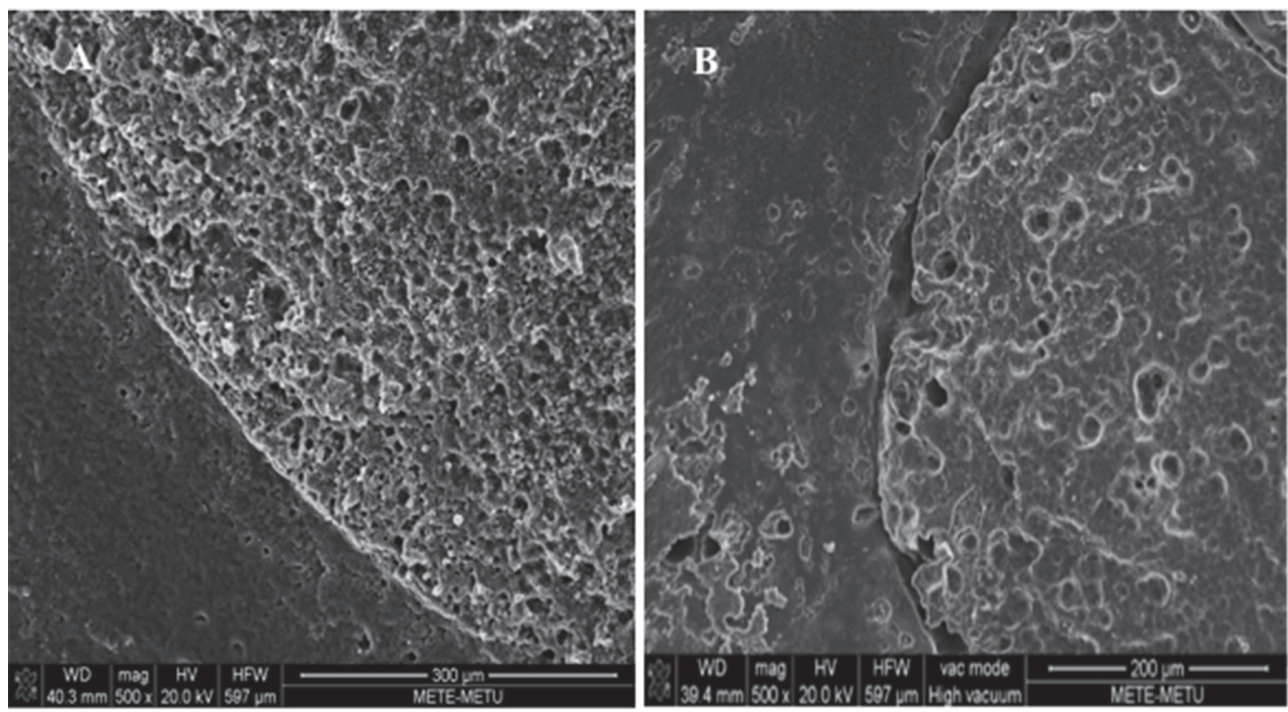

Fig. 2 Representative SEM images showing close marginal approximation in (A) and poor marginal approximation in (B) under 500× magnification. 
(Lloyd LR 30K, Fareham, UK) was used to apply a compressive vertical loading. A 3-mm diameter circular stainless steel rod was affixed to the upper stage of the machine, while the acrylic blocks were mounted on the lower platform. The tip of the rod was centered over the canal orifice and a slowly increasing vertical force parallel to the long axis of the tooth was exerted (1 $\mathrm{mm} / \mathrm{min})$ until fracture occurred. The force when the fracture occurred was recorded in Newtons and fracture modes were analyzed as restorable and catastrophic (non-restorable). The fractures located on the cervical third of the root were classified as restorable while the fractures on the middle or apical third of the roots were catastrophic.

\section{Statistical analysis}

Kruskal Wallis and Mann Whitney U tests were used to compare score values before and after backfillings of intergroup. Wilcoxon Signed Ranks test was used to compare the adaptation scores within groups. Fracture resistance values were compared with univariate analysis of variance (ANOVA) with Bonferroni correction. In all comparisons, $p$ value was set at 0.05 .

\section{RESULTS}

Figure 3 shows the distribution of marginal adaptation scores of samples before and after the backfilling procedures. According to that, Group DW presented similar marginal adaptation to Group PG $(p>0.05)$, while showed better adaptation than $\mathrm{CaCl}_{2}$ before and after backfilling with both techniques $(p<0.05)$. Group PG presented better marginal adaptation than Group $\mathrm{CaCl}_{2}$ before both backfilling techniques and after CLC $(p<0.05)$, while no significant difference was observed after WVC $(p>0.05)$. The only significant difference regarding marginal adaptation change due to the backfilling procedure was seen in $\mathrm{CaCl}_{2}$ after WVC $(p<0.05)$. Regardless of the plug materials, there was no significant difference after backfilling with CLC and WVC in terms of marginal adaptation $(p>0.05)$. The results regarding fracture testing are summarized in Table 1. The negative control group had the highest fracture resistance $(p<0.05)$. The positive control group did not differ significantly from the experimental groups $(p>0.05)$. Group PG-WVC showed significantly lower fracture resistance than Groups DW-WVC and PG-CLC $(p<0.05)$. No significant difference was found among the other experimental groups in regards of fracture resistance $(p>0.05)$. Regardless of the backfilling techniques, Group PG presented lower fracture resistance than Group DW $(p<0.05)$. All samples were fractured in catastrophic way and most of the fractures

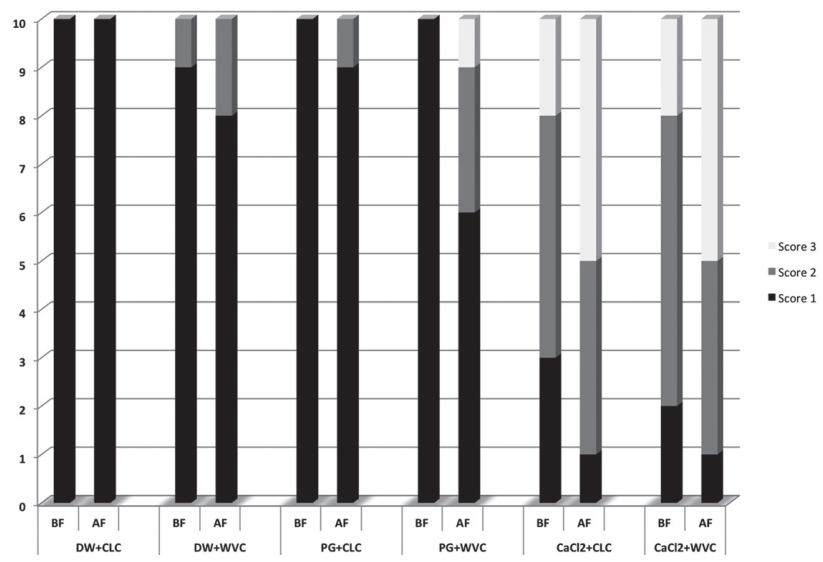

Fig. 3 Distribution of marginal adaptation scores of the experimental groups before and after backfilling. DW: distilled water; PG: propylene glycol; $\mathrm{CaCl}_{2}$ : calcium chloride; CLC: cold lateral compaction; WVC: warm vertical compaction.

Table 1 Fracture resistance values (Mean \pm Standard Deviation) in Newton and failure modes analysis of groups

\begin{tabular}{|c|c|c|c|c|}
\hline \multirow{2}{*}{ Groups } & \multirow{2}{*}{$\begin{array}{c}\text { Fracture resistance } \\
\text { values mean } \pm \mathrm{SD}(\mathrm{N})^{*}\end{array}$} & \multicolumn{3}{|c|}{ Failure modes } \\
\hline & & $\mathrm{C} / \mathrm{R}$ & $\mathrm{MD}$ & $\mathrm{LL}$ \\
\hline Negative control & $583.40 \pm 93.15^{\mathrm{a}}$ & $\mathrm{C}$ & 2 & 8 \\
\hline Positive control & $378.16 \pm 60.35^{\text {bc }}$ & $\mathrm{C}$ & 6 & 4 \\
\hline DW-CLC & $447.68 \pm 83.92^{\mathrm{b}}$ & $\mathrm{C}$ & 4 & 6 \\
\hline DW-WVC & $387.65 \pm 68.72^{\mathrm{b}}$ & $\mathrm{C}$ & 3 & 7 \\
\hline PG-CLC & $359.69 \pm 68.93^{\text {b }}$ & $\mathrm{C}$ & 2 & 8 \\
\hline PG-WVC & $288.84 \pm 81.76^{\mathrm{c}}$ & $\mathrm{C}$ & 6 & 4 \\
\hline $\mathrm{CaCl}_{2}-\mathrm{CLC}$ & $362.35 \pm 90.77^{\mathrm{b}}$ & $\mathrm{C}$ & 5 & 5 \\
\hline $\mathrm{CaCl}_{2}-\mathrm{WVC}$ & $350.69 \pm 34.57^{\text {bc }}$ & $\mathrm{C}$ & 2 & 8 \\
\hline
\end{tabular}

* Different letters mean statistically significant differences, $p<0.05$. C: catastrophic, R: restorable, MD: mesiodistal; LL: labiolingual 
were labiolingually.

\section{DISCUSSION}

The use of MTA as an artificial barrier in the treatment of necrotic teeth with immature apices is a wellestablished technique ${ }^{15}$. This treatment technique has been accomplished in several case reports by placing MTA plugs with a thickness of $3-5 \mathrm{~mm}$ and obturating the remaining root canal portion with cold lateral or warm vertical compaction techniques ${ }^{16-19)}$. Both obturation techniques may create different stresses and wedging effects inside the root canal system ${ }^{20,21)}$, thus may affect the marginal adaptation of apical plugs and also the fracture resistance of endodontically treated immature teeth. In the present study, we evaluated the effects of CLC and WVC techniques on the marginal adaptation and the fracture resistance of immature teeth obturated using MTA apical plugs with various additives.

Based on the results of the present study, PG and DW presented good marginal adaptation before and after both backfilling procedures. In a recent study, Duarte $e t a l .{ }^{22}$ ) found that the addition of PG, improved the flowability and the handling of MTA and they proposed $80 \% \mathrm{DW}-20 \% \mathrm{PG}$ as the optimum ratio. Also, in another study the same ratio was found to improve the push out bond strength of MTA ${ }^{8}$. Based on these studies, we decided to use this ratio for preparing PG in the present study. It was suggested that the addition of PG to MTA improves the consistency with more cohesiveness leading to easy manipulation and placement of the material into the defect site ${ }^{8}$. Although better handling property was obtained with PG compared to DW, no significant difference was found in their marginal adaptation to dentin in the present study. In regards to this finding, we can recommend the use of PG as an apexification material; however further research is necessary to evaluate the other properties of this mixture. In several studies, it was reported that the addition of $\mathrm{CaCl}_{2}$ accelerates the setting time of $\mathrm{MTA}^{9,10}$. Since the long setting time is one of the main disadvantages of MTA, the use of $\mathrm{CaCl}_{2}$ as an apexification material was considered as a reasonable choice in the present study. According to our results, $\mathrm{CaCl}_{2}$ presented poor marginal adaptation compared to PG and DW. Moreover, the marginal adaptation of MTA apical plug was only affected by the obturation technique when only mixed with $\mathrm{CaCl}_{2}$. In a recent study, the addition of $\mathrm{CaCl}_{2}$ was associated with a negative influence on the push-out bond strength of MTA to dentin ${ }^{9}$. The bond strength is responsible for resistance against procedural forces such as forces applied during the obturation of the root canal system ${ }^{8)}$. It is probable that lower bond strength of $\mathrm{CaCl}_{2}$ to dentin'), led to a negatively influenced marginal adaptation after the backfilling procedure. Furthermore, a previous study showed that the compressive strength of MTA obtained with the addition of $\mathrm{CaCl}_{2}$ was lower than MTA with $\mathrm{DW}^{10)}$. Since compressive strength is a property that indicates how a material bears under pressure, it can be another explanation why the material showed poor adaptation after the backfilling procedure. The addition of $\mathrm{CaCl}_{2}$ accelerates the setting of MTA and thus reduces the incorporation of water ${ }^{23}$. The changed powderliquid ratio may be responsible from poor marginal adaptation of MTA- $\mathrm{CaCl}_{2}$. Another interesting finding of the present study is that the adaptation of $\mathrm{CaCl}_{2}$ was affected by only WVC technique, while no significant difference was occurred after CLC technique. The stresses occurred during lateral or vertical compaction is a controversial topic in literature. Gimlin et al. ${ }^{24)}$ compared the lateral and vertical compaction forces using a mathematical model and found that lateral compaction was more likely to produce undesirable stress concentration than vertical compaction of guttapercha. On the other hand, a finite element analysis study showed that comparable magnitudes of stresses were occurred in dentin during both obturation techniques ${ }^{25}$. In the present study, only $\mathrm{CaCl}_{2}$ group showed altered marginal adaptation after WVC technique and this could be related to the direct forces applied by the plugger on the material. According to the literature, the wedging effect of a spreader during lateral compaction and the force application by a plugger during vertical compaction are both risk factors for stress concentration at localized $\operatorname{areas}^{20)}$. However, it is noteworthy to mention that the aforementioned studies represent the teeth with closed apices. Further research is necessary to evaluate the stress concentration and distribution during different obturation techniques in immature teeth with wide open apices.

For evaluation of the marginal adaptation, we performed SEM examination, which is a commonly used method in laboratory studies owing to its ability to provide high magnification and good resolution ${ }^{26-28}$. Importantly, the process of SEM preparation may affect the results because of the high vacuum evaporation and dehydration of the coating process of biological samples that can cause development of artifacts such as cracks in hard tissues and separation or lifting of the filling materials from the surrounding tooth structure ${ }^{26)}$. Furthermore, it is impossible to examine the same specimen with SEM before and after experimental procedures due to the coating process. To overcome these problems, we applied a replication technique by obtaining negative replicas of the original specimens using impression materials. Owing to this technique, we could examine the marginal adaptation of the same specimen before and after experimental procedures without any harm to the original specimens. In a previous study that evaluated quality of replication technique, low-viscosity silicones were found to be excellent materials for making impressions of tooth surfaces for SEM evaluation ${ }^{29}$. According to the quality and the resolution of the SEM images obtained in the present study, the use of negative replicas can be recommended for future studies especially when before and after procedure images are necessary.

Apexification treatment by using MTA plugs is 
highly successful ${ }^{16,30)}$ and possesses several advantages such as shorter treatment time, creation of a good apical seal and an apical barrier on which obturation material might be condensed ${ }^{30)}$. Despite these advantages, immature teeth are susceptible to fracture due to their thin and weak root canal walls ${ }^{4}$. Therefore, it is essential to select a material or an obturation technique that would substantially exert a reinforcing effect. In the present study, strengthening capacity of MTA plugs with different additives and obturation techniques were tested by evaluating the fracture resistance of the teeth. For this analysis, we chose teeth with similar dimensions, performed decoronization prior to experimentation to standardize the samples and applied only vertical load along the long axis of the root to obtain uniform distribution of the force in each sample. Thus, the results obtained do not reflect the clinical situation directly, but can provide a relative comparison among the plug materials and obturation techniques. Within the limitations of this study, results have shown that only the addition of PG to MTA caused significant differences in fracture strength values. The lower fracture strength values obtained by the DW-PG group can be related to the moisture alteration in dentin tissue. It is well known that MTA requires water to initiate the hydration reaction and the setting process ${ }^{22,31)}$. According to a recent study, the use of PG reduced the amount of water available for hydration and thus, the addition of PG increased the setting time of $\mathrm{MTA}^{22)}$. Therefore, the addition of PG to MTA may affect the water content of dentin negatively during the setting process, leading the tissues more susceptible to fracture. Furthermore, the force created by a plugger during vertical compaction may cause increased stress concentration at localized areas $^{20)}$ and could be associated with the further decrease in the fracture susceptibility of PG-WVC group.

\section{CONCLUSION}

Based on the results of this in vitro study, the both null hypotheses were rejected. The addition of $\mathrm{CaCl}_{2}$ negatively influenced the marginal adaptation of MTA while the addition of PG to MTA caused significant decrease in the fracture resistance. The WVC technique caused deterioration in the marginal adaptation of MTA mixed with $\mathrm{CaCl}_{2}$ and resulted in a significant decrease in the fracture resistance of teeth plugged with MTA/ PG mixture. The use of DW as an additive for preparing MTA apical plug in immature teeth can be recommended when the remaining root canal space is going to be filled with either CLC or WVC techniques.

\section{REFERENCES}

1) Andreasen FM, Andreasen JO, Bayer T. Prognosis of root-fractured permanent incisors - prediction of healing modalities. Endod Dent Traumatol 1989; 5: 11-22.

2) Frank AL. Therapy for the divergent pulpless tooth by continued apical formation. J Am Dent Assoc 1966; 72: 8793.

3) Kerekes K, Heide S, Jacobsen I. Follow-up examination of endodontic treatment in traumatized juvenile incisors. J Endod 1980; 6: 744-748.

4) Schmoldt SJ, Kirkpatrick TC, Rutledge RE, Yaccino JM. Reinforcement of simulated immature roots restored with composite resin, mineral trioxide aggregate, gutta-percha, or a fiber post after thermocycling. J Endod 2011; 37: 13901393.

5) Torabinejad M, Chivian N. Clinical applications of mineral trioxide aggregate. J Endod 1999; 25: 197-205.

6) Witherspoon DE, Ham K. One-visit apexification: technique for inducing root-end barrier formation in apical closures. Pract Proced Aesthet Dent 2001; 13: 455-460; quiz 462.

7) Torabinejad M, Parirokh M. Mineral trioxide aggregate: a comprehensive literature review - part II: leakage and biocompatibility investigations. J Endod 2010; 36: 190-202.

8) Salem Milani A, Froughreyhani M, Charchi Aghdam S, Pournaghiazar F, Asghari Jafarabadi M. Mixing with propylene glycol enhances the bond strength of mineral trioxide aggregate to dentin. J Endod 2013; 39: 1452-1455.

9) de Almeida J, Felippe MC, Bortoluzzi EA, Teixeira CS, Felippe WT. Influence of the exposure of MTA with and without calcium chloride to phosphate-buffered saline on the push-out bond strength to dentine. Int Endod J 2014; 47: 449453.

10) Prasad A, Pushpa S, Arunagiri D, Sawhny A, Misra A, Sujatha R. A comparative evaluation of the effect of various additives on selected physical properties of white mineral trioxide aggregate. J Conserv Dent 2015; 18: 237-241.

11) Tanalp J, Dikbas I, Malkondu O, Ersev H, Gungor T, Bayirli G. Comparison of the fracture resistance of simulated immature permanent teeth using various canal filling materials and fiber posts. Dent Traumatol 2012; 28: 457-464.

12) Araujo AC, Nunes E, Fonseca AA, Cortes MI, Horta MC, Silveira FF. Influence of smear layer removal and application mode of MTA on the marginal adaptation in immature teeth: a SEM analysis. Dent Traumatol 2013; 29: 212-217.

13) Tran D, He J, Glickman GN, Woodmansey KF. Comparative analysis of calcium silicate-based root filling materials using an open apex model. J Endod 2016; 42: 654-658.

14) Karapinar-Kazandag M, Basrani B, Tom-Kun Yamagishi V, Azarpazhooh A, Friedman S. Fracture resistance of simulated immature tooth roots reinforced with MTA or restorative materials. Dent Traumatol 2016; 32: 146-152.

15) Holden DT, Schwartz SA, Kirkpatrick TC, Schindler WG. Clinical outcomes of artificial root-end barriers with mineral trioxide aggregate in teeth with immature apices. J Endod 2008; 34: 812-817.

16) Pace R, Giuliani V, Pini Prato L, Baccetti T, Pagavino G. Apical plug technique using mineral trioxide aggregate: results from a case series. Int Endod J 2007; 40: 478-484.

17) Erdem AP, Sepet E. Mineral trioxide aggregate for obturation of maxillary central incisors with necrotic pulp and open apices. Dent Traumatol 2008; 24: e38-41.

18) Gunes B, Aydinbelge HA. Mineral trioxide aggregate apical plug method for the treatment of nonvital immature permanent maxillary incisors: Three case reports. J Conserv Dent 2012; 15: 73-76.

19) Sharma V, Sharma S, Dudeja P, Grover S. Endodontic management of nonvital permanent teeth having immature roots with one step apexification, using mineral trioxide aggregate apical plug and autogenous platelet-rich fibrin membrane as an internal matrix: Case series. Contemp Clin Dent 2016; 7: 67-70.

20) Blum JY, Machtou P, Micallef JP. Analysis of forces developed during obturations. Wedging effect: Part II. J Endod 1998; 24: 223-228.

21) Tang $\mathrm{W}, \mathrm{Wu} \mathrm{Y}$, Smales RJ. Identifying and reducing risks for potential fractures in endodontically treated teeth. J Endod 2010; 36: 609-617. 
22) Duarte MA, Alves de Aguiar K, Zeferino MA, Vivan RR, Ordinola-Zapata R, Tanomaru-Filho M, Weckwerth PH, Kuga MC. Evaluation of the propylene glycol association on some physical and chemical properties of mineral trioxide aggregate. Int Endod J 2012; 45: 565-570.

23) Bortoluzzi EA, Broon NJ, Bramante CM, Garcia RB, de Moraes IG, Bernardineli N. Sealing ability of MTA and radiopaque Portland cement with or without calcium chloride for root-end filling. J Endod 2006; 32: 897-900.

24) Gimlin DR, Parr CH, Aguirre-Ramirez G. A comparison of stresses produced during lateral and vertical condensation using engineering models. J Endod 1986; 12: 235-241.

25) Telli C, Gulkan P, Gunel H. A critical reevaluation of stresses generated during vertical and lateral condensation of guttapercha in the root canal. Endod Dent Traumatol 1994; 10: 1-10.

26) Torabinejad M, Smith PW, Kettering JD, Pitt Ford TR. Comparative investigation of marginal adaptation of mineral trioxide aggregate and other commonly used root-end filling materials. J Endod 1995; 21: 295-299.

27) Xavier CB, Weismann R, de Oliveira MG, Demarco FF, Pozza DH. Root-end filling materials: apical microleakage and marginal adaptation. J Endod 2005; 31: 539-542.

28) Badr AE. Marginal adaptation and cytotoxicity of bone cement compared with amalgam and mineral trioxide aggregate as root-end filling materials. J Endod 2010; 36: 1056-1060.

29) Galbany J, Estebaranz F, Martinez LM, Romero A, De Juan J, Turbón D, Pérez-Pérez A. Comparative analysis of dental enamel polyvinylsiloxane impression and polyurethane casting methods for SEM research. Microsc Res Tech 2006; 69: 246-252.

30) Witherspoon DE, Small JC, Regan JD, Nunn M. Retrospective analysis of open apex teeth obturated with mineral trioxide aggregate. J Endod 2008; 34: 1171-1176.

31) Marciano MA, Guimaraes BM, Amoroso-Silva P, Camilleri J, Hungaro Duarte MA. Physical and chemical properties and subcutaneous implantation of mineral trioxide aggregate mixed with propylene glycol. J Endod 2016; 42: 474-479. 